\title{
Avaliação do isolamento acústico em um templo religioso na cidade de Santarém Pará
}

\author{
Acoustic insulation assessment in a religious temple in Santarém \\ city - Pará
}

\author{
Manoel José Oliveira da \\ Cruz \\ manoel1109@hotmail. \\ com.br \\ Universidade Federal do \\ Oeste do Pará - UFOPA

\section{Dênio Ramam Carvalho de Oliveira \\ denio@ufpa.br \\ Universidade Federal do \\ Pará.}

\begin{abstract}
Resumo
O isolamento acústico de teatros, auditórios e casas de shows é de fundamental importância no âmbito social para que o funcionamento destes locais esteja de acordo com as técnicas aplicadas na engenharia civil e com o código de postura da cidade em questão. As situações decorrentes de uma da ineficiência do material empregado no isolamento acústico, associada a projetos arquitetônicos mal elaborados, podem acarretar um comprometimento da finalidade de um empreendimento ou estabelecimento, bem como causar seu embargo e fechamento. Este trabalho apresenta os resultados de medições de nível de ruídos em um templo religioso para viabilizar uma avaliação qualitativa de acordo com as normas técnicas nacionais e o Código de Postura do Município, além de uma proposta para isolamento acústico em estabelecimentos que precisam e devem funcionar "sem vazamentos sonoros" que possam vir a prejudicar o ambiente e a sociedade. Os níveis sonoros obtidos nos pontos periféricos foram a contento, dentro das normas técnicas exigidas, com uma variação de resultados mostrando uma eficiência de revestimento dentro de padrões de baixo custo e confortáveis ao ouvido humano.
\end{abstract}

Palavras-chave: Isolamento acústico. Ruído. Normas.

\begin{abstract}
The soundproofing of theaters, auditoriums and concert halls is of fundamental importance in the social sphere, so that the operation of these sites is in accordance with the techniques applied in civil engineering and code posture of the city concerned. The situations that arise with the inefficiency of the material used in associated with poorly designed architectural projects sound insulation can result in an impairment of the purpose of an enterprise or establishment; and cause its embargo and closing. This paper presents the results of measurements of noise level at a religious temple to enable a qualitative assessment in accordance with national technical standards and the Code of the County Posture plus a proposal for sound insulation in establishments that need and should work " without leaks sound " that may harm the environment and society. Noise levels were obtained in peripheral points to satisfaction within the required technical standards with a range of results showing coating efficiency standards within low cost and comfortable to the human ear.
\end{abstract}

Keywords: Soundproofing. Noise. Standards.

\section{Introdução}

Seguindo um raciocínio mundial de sustentabilidade para que o convívio social urbano esteja dentro dos padrões de intensidades sonoras acusticamente perfeitas, como determina a Associação Brasileira de Normas Técnicas (ABNT), o Código de Obras, o de Posturas do Município e o Código Ambiental do município de Santarém, no estado do Pará, procurase mostrar alguns recursos para isolamento acústico eficiente e que não comprometa uma execução complexa, corroborando para um contento de convívio tranquilo entre vizinhos. Enquanto as pesquisas no primeiro mundo se estabelecem com ordem, em alguns países do terceiro mundo essa política ainda não acontece, mas umas adaptações com elementos mais 
simples podem ter uma saudável consequência na engenharia acústica, deixando ambientes isolados com o mínimo de vazamentos de som ou ruído. O que se propõe neste artigo é um cuidado maior na execução e escolha de materiais comuns, adaptáveis e de sustentabilidade eficiente, para que se tenha na acústica um item intrínseco ao cotidiano de projetos que trabalhem com produção sonora considerável de qualquer espécie.

Com o intuito de provar essa viabilidade de cuidados de revestimento para um isolamento acústico a contento, escolheu-se uma igreja de grande porte, avizinhada de residências, num bairro central de Santarém-PA, pois ela não possui registro de reclamações na Secretaria Municipal de Meio Ambiente (SEMMA), órgão atuante na fiscalização urbana do município. Esse tipo de edificação é alvo, nas grandes cidades, de contínuas reclamações de vizinhos e populares que transitam em seu espaço comum; por isso, a engenharia civil, corroborando com uma arquitetura interna e externa, possui um contínuo trabalho de conforto acústico como missão objetiva, a fim de se enquadrar em um contexto social a contento para todos.

\section{Revisão Bibliográfica}

A reação dos seres humanos ao som pode ter uma conotação de ruído, segundo Bistafa (2006), baseando-se na subjetividade dessa classificação. O autor ainda afirma que existe uma dificuldade de avaliar quantitativamente o incômodo do ruído de acordo com a noção de audibilidade e aceitação do ouvinte e também do potencial intrusivo.

O conteúdo dos níveis sonoros, a complexidade do espectro, a duração, a amplitude, a frequência e o tempo de subida de sons impulsivos também seriam de importância considerável para a classificação. A sensibilidade auditiva a reflexões sonoras remete à habilidade humana de reconhecer os sons gerados na natureza, desenvolvida ao longo da evolução humana, e essa capacidade implica em ignorar o efeito do ambiente para perceber o som original, sendo isso uma audição seletiva que funciona como filtro para ruídos de qualquer espécie. Quando o ser humano é o produtor do som, tem-se um ajuste na produção sonora que seria dependente das características acústicas do ambiente; para uma audibilidade de sons impulsivos, os sons puros têm a mesma curva auditiva de um ruído ou ruídos e, numa sala destinada à palavra falada, tem-se o som das vogais tendendo a mascarar o som das consoantes, trazendo perda da inteligibilidade em frases. Para fundamentação de instrumentos de medições acústicas, Bistafa (2006) indica um sensor de pressão sonora eletroacústico, o microfone, que transforma a pressão sonora em um sinal elétrico equivalente ligado a um sonômetro, conhecido como decibelímetro. A regulamentação de níveis toleráveis é exigida pelo Código de Obras e Código de Posturas do município, que norteia as ações da fiscalização, deixando clara a necessidade desse controle para o convívio urbano.

Como descrito por Eniz e Garavelli (2006), o ruído urbano está cada vez mais presente no dia a dia das pessoas, em residências, locais de trabalho, ambientes de lazer, hospitais e escolas, podendo, e muito, prejudicar as relações sociais, a comunicação, o comportamento e até o rendimento escolar e/ou a saúde de moradores de grandes centros. Os considerados ruídos intensos, acima de $90 \mathrm{~dB}$, dificultam a audição em uma conversa de nível normal; algo em torno de $40 \mathrm{~dB}$. Pessoas precisam falar mais alto e prestar mais atenção para entender e serem ouvidas com clareza. Com isso, a tensão psicológica e o nível de atenção são prejudicados. Os ruídos intensos tendem a prejudicar tarefas que exigem concentração mental e algumas tarefas que exigem atenção ou velocidade e principalmente precisão de movimentos e tudo piora após duas horas de exposição ao ruído, como definido por Iida (1990).

O Código de Obras entra no isolamento acústico no capítulo XV que trata da classificação e dimensão dos compartimentos, seção I, art. 107, introduz os cuidados construtivos que diz que os compartimentos e ambientes deverão ser posicionados na edificação e dimensionados de forma a proporcionar conforto ambiental, térmico e acústico e proteção contra umidade, obtida no projeto pelo adequado dimensionamento e emprego dos materiais das paredes, coberturas, pavimentos, e aberturas, bem como das instalações e equipamentos. No capítulo XVI, seção I sobre iluminação, insolação e ventilação natural e isolamento acústico, art. 117, que diz que não é permitida ligação por aberturas e/ou elementos vazados entre locais ruidosos e áreas de estar ou locais que exijam condições ambientais assim como logradouros públicos e lote contíguo e que todas as edificações bem como suas instalações e equipamentos deverão receber tratamento acústico adequado de modo a não deixar vazar ruídos de qualquer natureza, assim como sistemas de segurança adequados, prevenindo à saúde do trabalhador e incômodos para a vizinhança. Continuando essa obrigatoriedade de cuidados construtivos no capítulo XVIII, dos materiais e elementos construtivos, seção I, elementos técnicos construtivos, art. 127, que as características técnicas são dos elementos usados na construção, referentes as qualidades e quantidades, condição de uso e a capacidade de reduzir vazamentos sonoros pelo seu trabalho conjugado. 
Os processos construtivos do Código de Obras são auxiliados pelo Código de Posturas do município que tende a manter a ordem no lado de fora das construções, como no capitulo II, art. 114, tem-se a referencia da tranquilidade pública, ratificada ao extremo quando incide que: é proibido perturbar o sossego e o bem-estar público, considerado atentado à tranquilidade pública qualquer ato de perturbação com ruídos ou sons excessivos de qualquer natureza. Uma complementação explícita, o art. 115 registra sobre instalação e funcionamento de qualquer tipo de aparelho sonoro que produza ruído qualquer, alerta/propaganda para o exterior dos estabelecimentos comerciais, industriais, prestadores de serviços e que dependam de Alvará da Prefeitura. Ainda no mesmo, tem-se que o estabelecimento deverá ser completamente adaptado em técnica de acústica, de modo a evitar propagação de som ao exterior, considerada ruidosa, em índices acima dos definidos pelas normas da ABNT, para que não haja perturbação do sossego público.

No que concerne à realização de música ao vivo em local totalmente aberto; somente com expedição de autorização pública para festas, eventos religiosos, festas juninas e eventos artísticos, esportivos, culturais e turísticos, etc. Se houver reclamações de perturbação qualquer, com comprovação; a autorização “... poderá ser suspensa ou revogada, sem prejuízo de outras sanções em processo administrativo contencioso a que se permitirá ampla defesa".

O Código de Posturas fecha um raciocínio de preservação e prevenção para coadunar com o Código de Obras, apoiando-se na ABNT no art. 116, quando tem explicito que a intensidade de som ou ruído, medida em decibéis, não poderá ser superior á estabelecida.

O continuado apoio do Código de Posturas vai ao Titulo IX, da poluição do meio ambiente, capitulo I, das disposições gerais, art. 235, onde se trata do cuidado sobre o meio ambiente direto para impedir ou atenuar a poluição, onde o poder público representado pela Prefeitura Municipal que tomará regulamento de acordo com os limites de ruídos permitidos pela ABNT.

Fechando as regulamentações ambientais referentes a som, tem-se no art. 245: onde se tem o trato de impedir ou reduzir a poluição proveniente de sons e ruídos excessivos, a administração pode adotar medidas como disciplinar a localização, residenciais ou comerciais, de estabelecimento cujas atividades produzam ruídos, sons excessivos ou incômodos e controlar o uso de aparelhos sonoros eletroacústico, bem como estabelecer horários de funcionamento noturno de construções e estabelecimentos que produzam ruídos incômodos ao sossego público.

Como pesquisado na página da web www.amplitudeacustica.com.br, a LEI $\mathrm{N}^{\circ} 126,6.938 / 81$ de 10 de maio de 1977, norma do CONAMA ajusta-se à competência que lhe foi dada sobre emissão de ruídos quaisquer, provenientes de indústrias, comércios, propagandas ou recreações, obedecerá, normas de saúde, sossego público estabelecidas nesta resolução, bem como dentro de templos, fora deles com práticas litúrgicas de qualquer credo e a NBR 10.152 (1987) determina que o nível de ruído em igrejas e templos deve ser de, no máximo, 50 decibéis.

A Lei Estadual no 10.100, de 17 de janeiro de 1990 (Publicação - Diário do Executivo - "Minas Gerais" - 18/01/1990), deu nova redação ao artigo $2^{\circ}$ desta Lei, que no original limitava a 85(oitenta e cinco) decibéis o limite sonoro de emissão no exterior e no recinto de origem, e de acordo com o método MB-268, prescrito pela Associação Brasileira de Normas Técnicas e também se alcancem, no interior do recinto em que têm origem, níveis de sons superiores aos considerados normais pela Associação Brasileira de Normas Técnicas.

As Resoluções CONAMA nº 01 e a nº 02, de 08 de março de 1990 (Publicação - Diário Oficial da União 02/04/1990) dispõem sobre a emissão de ruídos, em decorrência de quaisquer atividades industriais, comerciais, sociais ou recreativas, determinando padrões, critérios e diretrizes e instituem um programa nacional de educação para controle da poluição sonora induzindo com isso a lei do silêncio. Sendo, dessa forma, um continuísmo de normas para um cuidado acústico de primeira necessidade em que a população deve se orientar em alguns tipos de empreendimentos; sendo apreciada em muitos países da Europa de maneira latente para um conjunto de direitos de cidadania urbana. A sociedade contemporânea se apoia em regras de convivência humana e técnicas normativas baseadas na arquitetura e engenharia civil para contento de um viver social provido de limites e harmonia de entendimento entre vizinhos. A Tabela 01 baseiase em uma comparação entre o nível de pressão sonora corrigido e o nível de critério de avaliação (NCA), segundo NBR 10151 (ABNT, 2000). A Tabela 02 apresenta os valores de ruídos conforme determina a NBR 10152 (ABNT, 1987). 
Tabela 01 - Nível de critério para avaliação NCA para ambientes externos, em db(A)

\begin{tabular}{lll}
\hline Tipo de áreas & Diurno & Noturno \\
\hline Área de sítio e fazendas & 40 & 35 \\
Área estritamente residencial urbana ou de hospitais ou de escolas & 50 & 45 \\
Área mista, predominantemente residencial. & 55 & 50 \\
Área mista, com vocação comercial e administrativa. & 60 & 55 \\
Área mista, com vocação recreacional. & 65 & 55 \\
Área predominantemente industrial. & 70 & 60 \\
\hline
\end{tabular}

Fonte: ABNT, 2000

Tabela 02 - Valores $\mathrm{dB}(\mathrm{A})$ e $\mathrm{NC}$

\begin{tabular}{lll}
\hline Locais & dB(A) & NC \\
\hline Hospitais & & $30-40$ \\
Apartamentos, Enfermarias, Berçários, Centro Cirúrgicos, & $35-45$ & $35-45$ \\
Laboratórios, área do público. & $40-50$ & $40-50$ \\
Serviço & $45-55$ & \\
Escolas & & $30-40$ \\
Bibliotecas, Sala de música, Sala de desenho. & $35-45$ & $35-45$ \\
Salas de aula, Laboratório. & $40-50$ & $40-50$ \\
Circulação & $45-55$ & \\
Hotéis & & $30-40$ \\
Apartamentos & & $35-45$ \\
Restaurantes, Sala de Estar. & $35-45$ & $40-50$ \\
Portaria, Recepção, Circulação. & $40-50$ & \\
Residências & $45-55$ & $30-40$ \\
Dormitórios & & $35-45$ \\
Sala de Estar & $35-45$ & \\
Auditórios & $40-50$ & $25-30$ \\
Sala de concertos, Teatros. & & $30-35$ \\
Sala de conferências, Cinema, Salas de múltiplo uso. & & $35-45$ \\
Restaurantes & $30-40$ & \\
Escritórios & $35-45$ & $25-30$ \\
Salas de reunião & $40-50$ & $30-35$ \\
Salas de gerência, salas de projeto e administração. & & $40-60$ \\
Sala de computadores & & $45-65$ \\
Sala de mecanografia & & $35-45$ \\
Lgrejas e Templos (cultos mediativos) & $30-40$ & \\
Locais para esporte & $35-45$ & $40-55$ \\
\hline
\end{tabular}

Fonte: ABNT, 2000.

a) O valor inferior da faixa representa o nível sonoro para conforto, enquanto que o valor superior significa o nível sonoro aceitável para esta finalidade.

b) Níveis superiores aos estabelecidos nesta tabela são considerados de desconforto, sem necessariamente implicar risco de dano à saúde.

Em alguns ambientes os diversos sons emitidos possuem interesses selecionados para determinadas frequências; fazendo-se assim a necessária correção de algumas delas que não são interessantes e, são considerados ruídos. Segundo 
a NBR 10152 (ABNT), o método de avaliação recomendado é baseado nas medições do nível sonoro dB(A); todavia, a análise de frequência de um ruído se faz necessária para correção do mesmo. Sempre é importante para objetivos de avaliação e adoção de medidas de correção ou redução do nível sonoro. Assim sendo, incluem-se na Fig. 01 várias curvas de avaliação de ruídos (NC), através das quais um espectro sonoro pode ser comparado, permitindo uma identificação das bandas de frequências mais significativas e que necessitam de correção. A Tabela 03, de acordo com a NBR 10152 (ABNT, 1987), apresenta os níveis de várias frequências sonoras para nortear uma seleção de sons ou ruídos emitidos pela música executada ao vivo nos Templos.

Figura 1 - Análise de frequência.

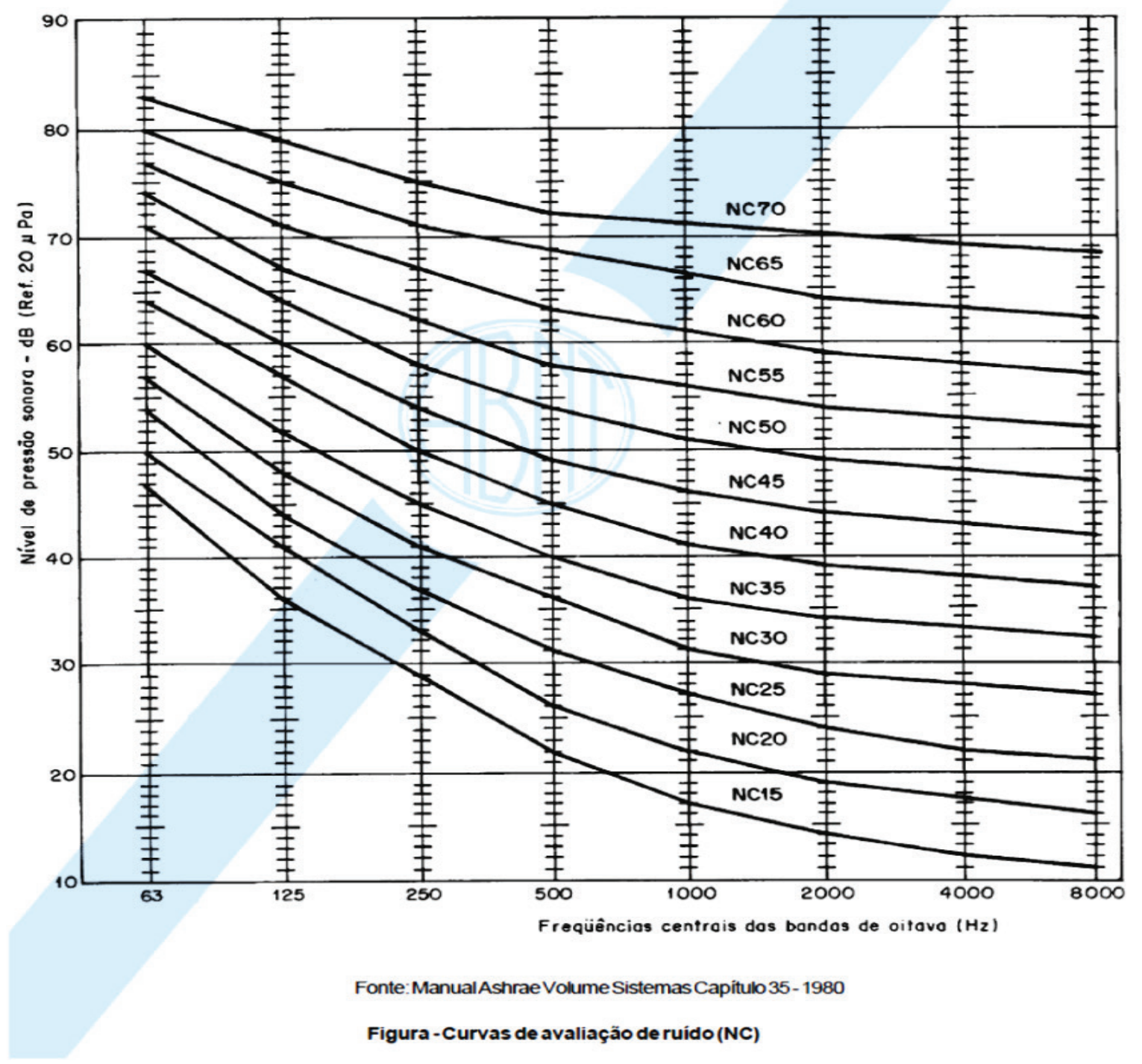

Fonte: ABNT, 1987. 
Tabela 03 - Níveis de pressão sonora correspondentes às curvas de avaliação (NC).

\begin{tabular}{ccccccccc}
\hline Curva & $\mathbf{6 3} \mathbf{~ H z ~ d B}$ & $\mathbf{1 2 5} \mathbf{~ H z ~ d B}$ & $\mathbf{2 5 0} \mathbf{~ H z ~ d B}$ & $\mathbf{5 0 0} \mathbf{~ H z ~ d B}$ & $\mathbf{1 ~ k H z ~ d B}$ & $\mathbf{2} \mathbf{~ k H z ~ d B}$ & $\mathbf{4} \mathbf{~ k H z} \mathbf{~ d B}$ & $\mathbf{5 ~ k H z ~ d B}$ \\
\hline 15 & 47 & 36 & 29 & 22 & 17 & 14 & 12 & 11 \\
20 & 50 & 41 & 33 & 26 & 22 & 19 & 17 & 16 \\
25 & 54 & 44 & 37 & 31 & 27 & 24 & 22 & 21 \\
30 & 57 & 48 & 41 & 36 & 31 & 29 & 28 & 27 \\
35 & 60 & 52 & 45 & 40 & 36 & 34 & 33 & 32 \\
40 & 64 & 57 & 50 & 45 & 41 & 39 & 38 & 37 \\
45 & 67 & 60 & 54 & 49 & 46 & 44 & 43 & 42 \\
50 & 71 & 64 & 58 & 54 & 51 & 49 & 48 & 47 \\
55 & 74 & 67 & 62 & 58 & 56 & 54 & 53 & 52 \\
60 & 77 & 71 & 67 & 63 & 61 & 59 & 58 & 57 \\
65 & 80 & 75 & 71 & 68 & 66 & 64 & 63 & 62 \\
70 & 83 & 79 & 75 & 72 & 71 & 70 & 69 & 68 \\
\hline
\end{tabular}

Fonte: ABNT, 2000.

Dentro da mecânica das tabelas tem-se uma amplitude de volume sonoro pela Tabela 03 , que vai de $45 \mathrm{~dB}$ até $83 \mathrm{db}$, explicitado no eixo vertical. Esta tabela possui esse parâmetro por causa do limite de suporte do ouvido humano. Algo com mais de $90 \mathrm{~dB}$ causaria danos com uma exposição acima de duas horas. Na mesma tabela, no eixo horizontal, tem-se a amplitude de frequencia sonora em Hertz. O ouvido humano só capta frequências do espectro sonoro de $20 \mathrm{~Hz}$ à 20.000 $\mathrm{Hz}$ (ou $20 \mathrm{kHz}$ ).

A faixa a ser trabalhada para os sons emitidos vai de $40 \mathrm{~Hz}$ ate' $1000 \mathrm{~Hz}$ ( que são os emitidos pela banda e público) e, está dentro destes limites audíveis.

Juntando essas informações tem-se um espaço amostral no meio do gráfico onde está a atuação sonora em questão no templo.

No templo com banda ao vivo, tem-se a necessidade de uma análise da gama de frequências relativa aos instrumentos mais comuns usados nesta atividade musical; por que uma banda com formação básica teria, em relação à frequência captada pelo ouvido humano, três instrumentos que cercariam as frequências graves, médias e agudas. A formação básica para uma banda seria um contrabaixo, uma guitarra elétrica e uma bateria acústica. O contrabaixo atingiria frequências menores em torno de $40 \mathrm{HZ}$ até $300 \mathrm{HZ}$ e a Guitarra elétrica emitindo algo entre $90 \mathrm{HZ}$ e 1.0KHZ; a bateria é o instrumento mais completo, compreendendo as frequências do contra baixo (no bumbo, nos ton-tons e surdo ficam as frequências baixas; na caixa seriam as frequências médias e nos pratos as frequências altas) desse modo, com essa classificação, é possível uma investigação direcionada de isolamento acústico para maior eficiência contra "vazamentos" e lembrando que o estudo em questão requer cuidado de registrar a eficiência do revestimento da igreja, de maneira a preservar o sossego de arredores. Moscatti (2013) fez um trabalho inverso para que o ruído vindo da rua não atribulasse o culto religioso. Como especificado, o interesse é captar os sons de "pico" no interior da igreja e analisá-los fora, de modo a um comparativo normativo.

\section{Materiais e métodos}

Os materiais usados foram pesquisados no mercado de "comuns" na execução de revestimento, de modo a isolar, por absorção, as frequências citadas no estudo do templo. Estes materiais foram descritos por técnicos entrevistados no local que inclusive, apontaram e quantizaram dimensões e processos executados quando na construção da igreja, sob supervisão de um arquiteto, para maior controle de eficiência. As paredes frontais do edifício, de um pavimento térreo, fazem fronteira com uma avenida cujo movimento de veículos e pedestres é intenso. Estas foram executadas com 600,0 $\mathrm{mm}$ de espessura, em alvenaria com argamassas de emboço $(15,0 \mathrm{~mm})$ e reboco $(20,0 \mathrm{~mm}) \mathrm{sem}$ cal e possui portas de vidro temperado escuro $(15,0 \mathrm{~mm})$ por onde se realiza a entrada e saída de pessoa, representados na fig. 2 . 
Figura 2 - Espessura da alvenaria externa do templo (Fotografia: Manoel Cruz - acervo pessoal)
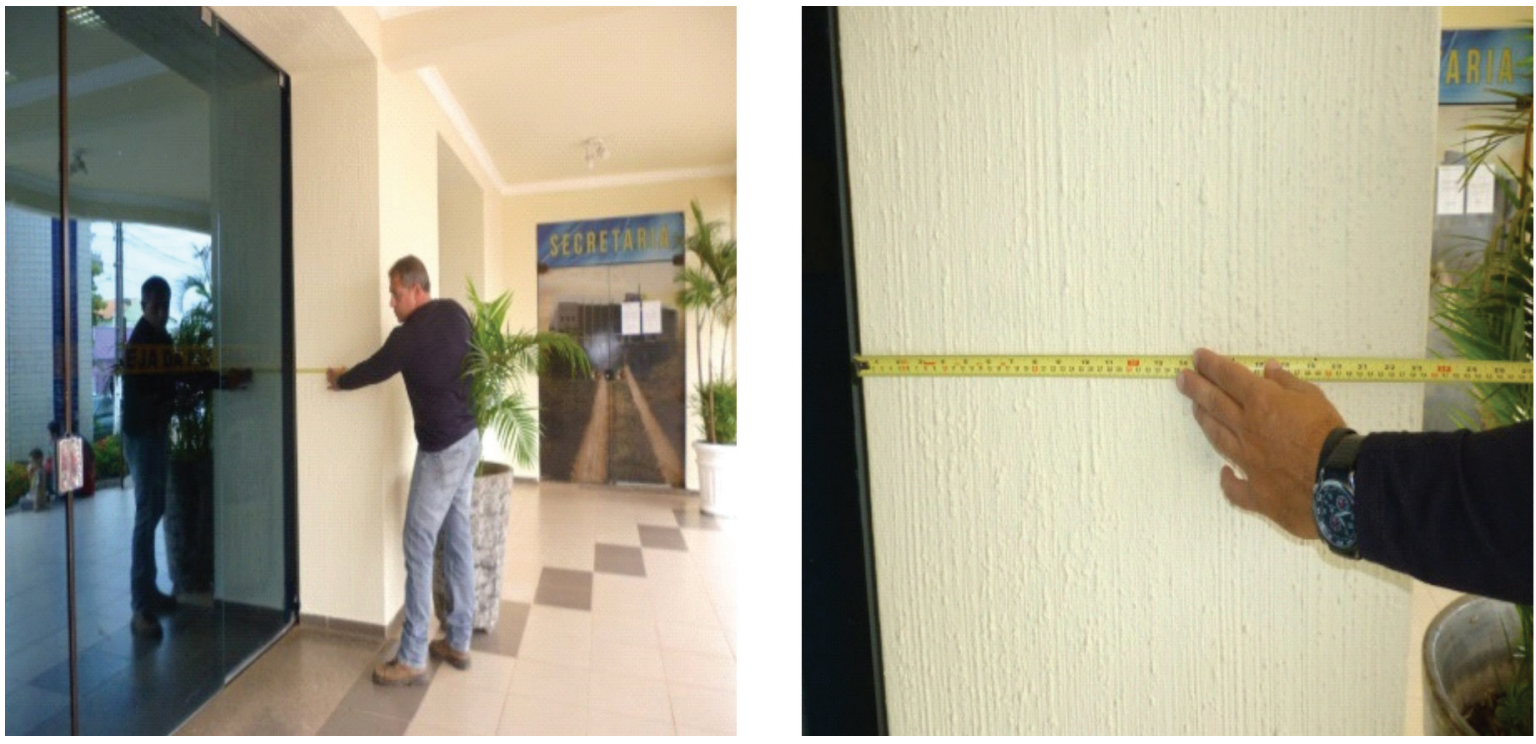

Este prédio de pavimento único térreo possui uma área útil de $(26,0 \times 26,0) \mathrm{m}^{2}$, onde ficam o público e um palco de $(5,0 \times 26,0) \mathrm{m}^{2}$, onde a banda e o coral com o pastor realizam o culto; perfazendo uma área de $806,0 \mathrm{~m}^{2}$ aproximadamente. Sendo que, as paredes laterais da edificação que ficam por trás do palco tiveram um cuidado específico de tratamento mais elaborado, quando foram revestidas com materiais de modo a trabalharem juntos com absorção sonora e impedindo assim que haja propagação excessiva às laterais avizinhadas, já que o prédio é localizado no meio de um quarteirão residencial.

Os revestimentos foram colocados em alvenaria a singelo, emboço de $15,0 \mathrm{~mm}$ e reboco de $25,0 \mathrm{~mm}$ do lado externo, onde se tem o limite de vizinhança e, os revestimentos referentes ao interior da igreja foram de telas de isopor de 15,0 mm colocadas em contato na superfície da alvenaria, com tela de arame para sustentação de 2,0 mm de diâmetro o fio, na qual foi aplicado um reboco de massa "forte" de 30,0 $\mathrm{mm}$, que após secagem de 24 horas teve um acabamento final em colagem de carpete azul de 4,0 $\mathrm{mm}$, perfazendo um total de $301,0 \mathrm{~mm}$ de parede externa. O revestimento do teto foi feito em isopor de $10,0 \mathrm{~mm}$ acompanhando o arco feito pelo telhado, como mostra na fig. 3. Este forro apresentou persianas atenuadoras de ruídos a cada 3,0 metros dispostas em todo o salão.

Figura 3 - Revestimento do teto do templo (Fotografia: Manoel Cruz - Acervo pessoal)

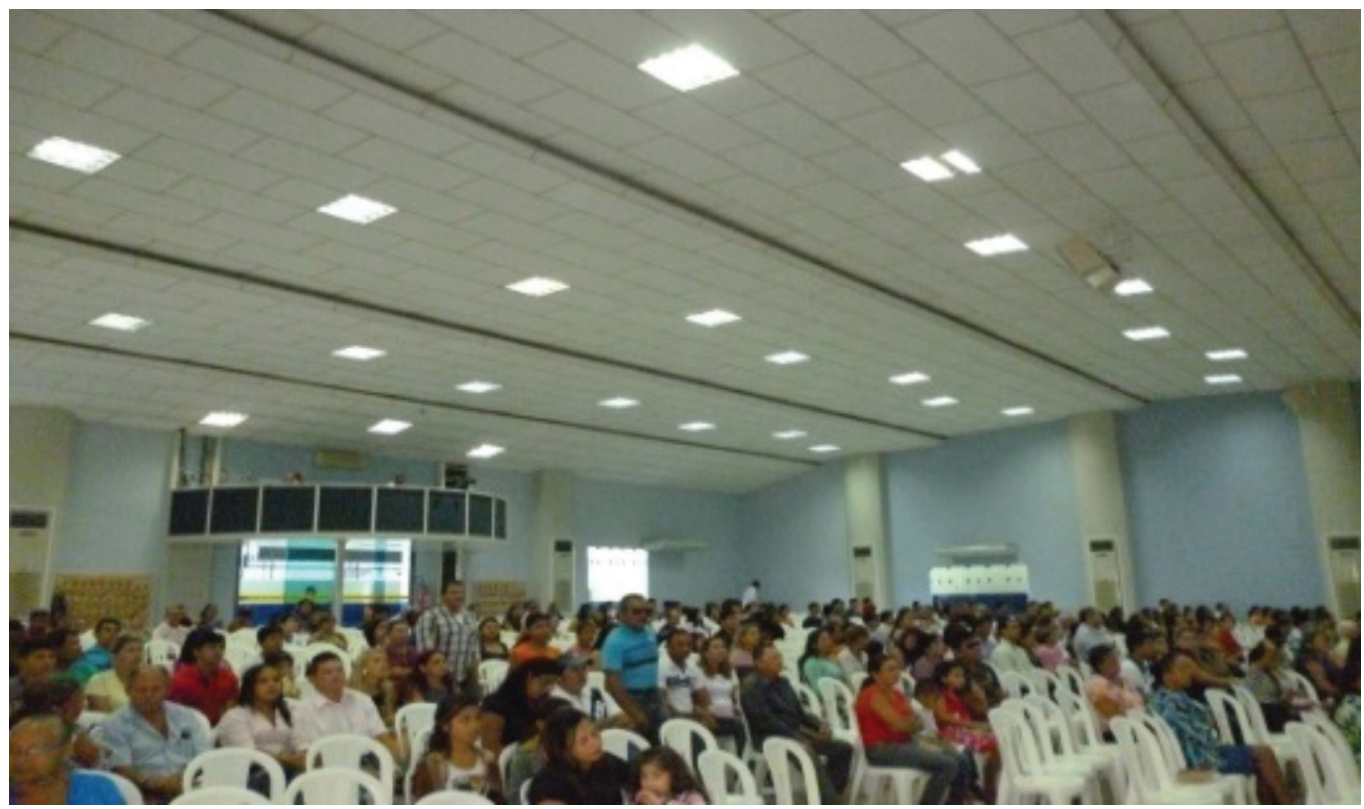


As medições sonoras foram feitas pelo técnico credenciado, da Secretaria Municipal de Meio Ambiente (SEMMA), segundo as especificações da NBR 10151 (ABNT, 2000), NBR 10152 (ABNT, 1987) e Lei 17894(2004) do Código Ambiental de Santarém, em seu artigo 154.

Estas medições foram feitas na parte externa do prédio; no passeio público ou calçada obedecendo à norma citada de 2,0 metros do limite da propriedade e de quaisquer superfícies refletoras e a 1,2 metro de altura conforme instruções do fabricante do medidor de intensidade sonora, o "decibelímetro". O Instrumento de medição da marca ICEL Manaus, modelo DL-4090, No 030703388 estava atendendo as especificações da IEC-80942, mostrado na Figs. 4a e 4b:

Figura 4 - Decibelímetro utilizado nas aferições. (Fotografia: Manoel Cruz - Acervo pessoal)
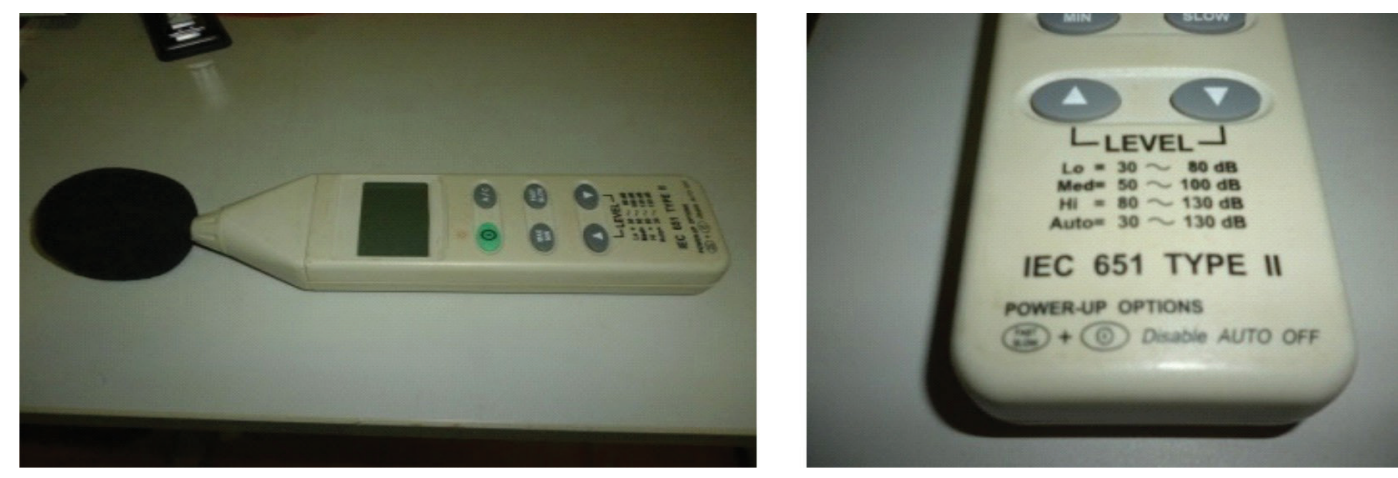

As medições internas, próximas à fonte de emissão estavam de acordo com o item 5.3 da NBR-10151(ABNT, 2000), que indica a distância de 1,0 metro de quaisquer superfícies como teto, pisos e móveis.

\section{Resultados e discussões}

Assim como qualquer ciência, a acústica sofreu globalização para conferir condições de vida melhor, se adaptando a realidades diferentes, alternativas com desafios marcados por novos materiais de revestimento a se adaptarem à cada realidade específica. Dessa forma, novas tecnologias têm surgido como soluções técnicas muitas vezes não divulgadas na mídia, deixando assim a desejar para um estabelecimento; que necessita de um conforto acústico adaptável, eficiente e com custo benefício sustentável.

O que se observa, principalmente em cidades menos desenvolvidas, é um descaso com a acústica de edificações dificultando o melhoramento destas condições. Mas à medida que essas transformações acontecem, o profissional da construção civil, tanto arquitetos quanto engenheiros, têm como desafios novas exigências em que tipo de projeto deve ter qual tipo de isolamento acústico compatível com sua função social. Enquanto as pesquisas em países desenvolvidos se estabelecem como ordem, em alguns países subdesenvolvidos isso não acontece, mas uma adaptação com elementos mais simples podem ter uma saudável consequência na engenharia acústica deixando ambientes isolados com o mínimo de vazamentos de som e ruído; e, em cidades, de um modo geral, tem-se uma grande quantidade de reclamações registradas em órgão públicos, referentes a excessos de ruídos por atividades diversas e/ou por constante passagem de veículos em determinado ponto crítico do trânsito.

As secretarias que trabalham diretamente com esse tipo de atividade são chamadas de "Ambientais", a exemplo de Santarém no estado do Pará, procura-se educar a população nesse específico sentido de poluição sonora excessiva que consiste numa veemente peleja noturna de técnicos em finais de semana.

Os três tipos específicos de poluição sonora são: ruídos de transito, ruídos produzidos no centro comercial e os produzidos em casas de atividades coletivas com manifestações de composições instrumentais diversas. Estas últimas fazem parte de um leque de possibilidades como boates, teatros, cinemas e igrejas.

As situações todas necessárias de âmbito social integram com continuo convívio e, para isso, os ambientes devem ser respeitados. Os cinemas não costumam ter vazamentos sonoros, mesmo com toda a potência dos sistemas de som internos que, em alguns casos chegam a atingir $110 \mathrm{~dB}$ de pico em cenas de explosões de filmes de ação e as igrejas não podem ser diferentes, como estabelecimentos que promovem um tipo de atividade que usa amplificação sonora, até por 
necessidade física, devido as suas dimensões. De maneira geral têm-se atividades evangélicas de alto teor sonoro com a participação de bandas em cultos e missas; o que deixa um necessário isolamento do mundo exterior bastante evidente.

Quando existe qualquer área do conhecimento envolvida, as palavras "específicas", "especial” ou "especialista" são sinônimas de custo elevado, o que normalmente levam o cliente a se preparar para um acréscimo na soma investida, ou seja, nos custos e o isolamento acústico sofre esse tipo de discriminação ainda hoje, com todo o aparato disseminado na mídia sobre uma sociedade mais social, globalizada, tolerante, comunitária; em que tudo deve funcionar como parte de um contexto de modo que não se tenha o prejudicial como parte de convivência e sim, o profissionalismo de técnicas apuradas para uma "obra" que funcione em consonância com as normas técnicas estabelecidas.

As condições que se buscam para todos os estabelecimentos que trabalham com um volume sonoro maior que uma conversa entre pessoas ( $60 \mathrm{~dB})$, é que tenham um tratamento acústico preocupado com vazamentos para prédios adjacentes e pedestres; sem forçá-los a participar de algum movimento sonora interno, transformando isso num transtorno; como mencionado na Lei do silêncio - Lei n ${ }^{\circ} 126$, de 10 de maio de 1977, em que o que se tem para uma sustentabilidade de tolerância auditiva social são níveis de conforto sonoro para a audição humana.

A emissão de ruídos de qualquer tipo coloca o direito de sossego público em confronto com a saúde da população em geral e a necessidade de contenção sonora se faz presente para um convívio urbano na medida em que existem normas técnicas de medição de ruídos com critérios específicos. Neste conjunto de fatos surgem opções de tratamento e isolamento acústico que visam à organização e direcionamento de uma quantidade sonora considerável.

Como postulado em definições diversas de isolamento acústico, devem-se ter condições ter uma boa noite, leitura, estudos e/ou qualquer outra atividade que faça parte do direito individual garantido pela cidadania. Em situações mais extremas; têm-se enfermidades que não escolhem hora e nem lugar para ocorrerem. Então, não faltam exemplos em que um recinto de eventos, com padrão de intensidade sonora elevado, irá produzir considerável incomodo se houver "vazamentos sonoros":

A questão envolta em um investimento para revestimento acústico deve ser vista como um único incômodo para um gozo de tranquilidade profissional ou familiar no futuro. Sem incômodos com "abaixo assinados" e fiscalizações de Secretarias do Meio Ambiente Municipais com exigências de adaptações que recaem em reformas civis, cujo custo tem maior valor agregado; como visto no site: www.amplitudeacustica.com.br, que diz que, a lei do silencio é um direito do cidadão e está presente no código civil.

Quanto à como se realiza os encontros religiosos, tem-se o direito fundamental do indivíduo, observado no artigo $5^{\circ}$ da Constituição da República Federativa do Brasil, no inciso VI. Mesmo visto esse direito, este não autoriza a atividades de ruídos excessivos com vizinhança ativa, ou seja, não dá permissão a ninguém para poluição sonora e a liberdade de cultos religiosos deve ser adaptada a NBR 10152 (ABNT, 1987) para que a tolerância seja palavra de ordem. Quando nisso, tem-se então o princípio de um reconhecimento da necessidade de um tratamento acústico local. Neste quesito chega-se a necessidade de um isolamento acústico, cuja definição é a não passagem de som de um ambiente para o outro. Isto requer cuidados específicos através do uso de materiais adequados para este fim.

Quando se quer isolar um som deve-se ter o cuidado com reflexões sonoras, pois estas produzem "eco" e, na maioria das vezes não é bem-vindo. Quando este som produz ainda variação, tem-se reverberação sonora, a qual soa como vários sons emitidos com certo atraso. Conhecido no meio eletrônico-acústico-musical como delay. O que se faz necessário então, é um tratamento acústico para evitar o "eco" dentro do estabelecimento com atenuadores de ruídos; que no caso escolhido, foram do tipo persianas, fixadas no teto, como foi descrito anteriormente no item 3 (materiais e métodos).

Outra grande preocupação é a absorção sonora nas paredes esta é tida como de alto custo, pois precisa de material com grande massa ou alta densidade para reter a energia cinética produzida pelas ondas sonoras. Foram observados em experiências que é importante se terem várias barreiras sonoras, que funcionaram como obstáculos de densidades diferentes a fim de obrigar o som a mudar de velocidade de vibração molecular na refração (passagem da onda sonora de um meio para outro). Estas, no caso estudado, foram feitas com materiais comuns na "praça", sem qualquer dificuldade de obtenção dos mesmos. Descritos no item 3 "Materiais e métodos", eles são tijolos, isopor, argamassa de cimento, malha de ferro e carpete; fazendo assim a diversidade de barreiras para propagação sonora do ambiente interno da igreja para o externo, rua e vizinhança. Sendo importante frisar que os elementos usados como isolantes não devem se tocar diretamente; usando para isso espumas e borrachas.

No caso mencionado como objeto de estudo, foram usadas folhas de isopor para garantir uma rigidez vertical devido ao seu encaixe e leveza no manuseio. A facilidade de encontrá-los no mercado e a familiaridade que eles possuem com os 
mestres de obra e técnicos aplicadores é que deixam o trabalho mais fácil. Embora o cuidado com frestas seja importante contra "vazamentos", pois pode prejudicar todo o trabalho de isolamento; é um ponto de atenção em portas com seus caixilhos e janelas para aplicação de espumas e borrachas mantendo a estanqueidade do ambiente.

O grande problema que se discute na eficiência do isolamento acústico de qualquer ambiente é que "vazamentos sonoros" são "ruídos sonoros" para viventes adjacentes. E a classificação de "ruídos" é de certa forma subjetiva, ou seja, depende de quem ouve. Segundo Gonçalves (1989): “(...) Som é o efeito produzido por ondas mecânicas longitudinais capazes de pressionar o ouvido humano e quando uma onda sonora é muito irregular é chamada de ruído".

Casos comuns de classificações de um mesmo som são discutíveis. Enquanto para uns, permanece a definição clássica musical que diz que ruídos são sons em desarmonia; Iida (1990) afirma que ruído nada mais é do que um som indesejável, o que torna discutível o "para quem é indesejável?". Casos de ensaios de bandas, shows de qualquer espécie e cultos fazem o "comum" neste tipo de reclamação quando estas são oficializadas. E a verificação de reclamantes pelo órgão competente tem um intuito nobre de se saber em que tipo de caso ela vai ser diagnosticada. Há registros de reclamações de idosos de sons classificados de baixa frequência para registros humanos, algo em torno de $20 \mathrm{~Hz}$, que só foi possível com uso de aparelho digital.

O Código de Obras, no seu art. 107, de dezembro de 2012, deixa claro que "Os compartimentos e ambientes deverão ser posicionados na edificação e dimensionados de forma a proporcionar conforto ambiental, térmico e acústico..." e no art. 117 tem-se que as edificações “... deverão receber tratamento acústico adequado...”; isso também é reforçado no art. 127 que registra a avaliação pela capacidade do elemento construtivo de atenuar e absorver ruídos. Isso tudo no Código de Posturas do Município é responsável pela organização legal do comportamento social de uma cidade e se apoia em normas técnicas para isso.

Com os artigos direcionados para este fim, o art. 114 sobre "Tranquilidade pública" proíbe a perturbação do sossego público e bem-estar da vizinhança em relação aos ruídos e sons produzidos e o art. 115 dispõe da dependência de licença prévia da prefeitura sobre funcionamento de aparelho sonoro e, especificamente no segundo parágrafo sobre música ao vivo; vindo seguido do art. 116 sobre a medição destes ruídos e sons sob os critérios da ABNT. De maneira geral e com o âmbito ambiental explicito; o art. 235 deixa clara a obrigação da prefeitura que fixará regulamento para "impedir ou reduzir a poluição do meio ambiente...”.

O último artigo do Código de Posturas Municipal é o 245 que posta: “[...] disciplinar e controlar o uso de aparelhos de reprodução eletroacústicos em geral". A tolerância humana para um conforto auditivo foi estudada e classificada, para áreas externas, segundo a NBR 10151 (ABNT, 2000). Onde numa área mista limita-se a $65 \mathrm{~dB}$ em ambientes externos.

As medições de ruídos ou qualquer outro tipo de som a ser classificado e estudado devem ser criteriosos, pois, qualquer tipo de erro ou interferência invalida resultados tornando toda a pesquisa não confiável. As medições foram feitas de acordo com o horário de pico da utilização do estabelecimento que, devido ao mês dezembro e janeiro teve um comparecimento maciço de pessoas, deixando assim a verificação confiável.

A tabela mostrada na NBR 10152 (ABNT, 1987), que é uma atualização da NBR 10151 (ABNT, 2000) sobre análise de ruídos ( $\mathrm{Nc}$ ), define de 40 a $50 \mathrm{~dB}$ para encontros religiosos.

A função-mor da norma sobre acústica em áreas habitadas, respeitando os limites de ruídos urbanos, deve adequar templos e igrejas a um tratamento de isolamento acústico a contento para a vizinha respectiva, de acordo com Moscatti (2003). O autor cita ainda três grupos de atividades que são bares-restaurantes, igrejas e vizinhos; devidamente discriminadas por Araújo (2005), do INMETRO-Brasil.

As medições deste trabalho foram feitas para uma verificação de compatibilidade de valores na unidade adotada, $o$ decibel $(\mathrm{dB})$. Os dados mínimos e máximos colhidos nas medições feitas foram:

Dentro do templo: $84 \mathrm{~dB}$ durante as pregações e $114 \mathrm{~dB}$ nos louvores com a banda da igreja tocando no altar. Deste modo, tem-se um volume de som excessivo emitido no interior do templo; segundo a Tabela 02 da ABNT 10152 (1987), a emissão sonora no interior de Templos não deverá ultrapassar $50 \mathrm{~dB}$.

No passeio público: $40 \mathrm{~dB}$ correspondentes as pregações e $65 \mathrm{~dB}$ registrados no louvor com a banda tocando.

Vizinhos: $35 \mathrm{~dB}$ registrados para as pregações e $50 \mathrm{~dB}$ para louvores com a banda. Pela Tabela 01 da ABNT (2000), em áreas mistas predominantemente residenciais, o máximo permitido durante o dia é $55 \mathrm{~dB}$.

Nos intervalos, teve-se variância bastante irregular entre esses valores mínimos e máximos, tomando-se sempre o cuidado para registrar cada um deles e não perder o registro de picos, tornando esses registros dentro do que se exige para a classificação de confiabilidade irrestrita exigida pelas normas. 


\section{Conclusão}

A grande questão discutida neste trabalho é de como pode ser feito um isolamento acústico sem que se tenha uma gama de materiais de custo elevado envolvidos neste fim. A falta de igrejas e templos e até casas de shows, com acústica à prova de vazamentos, segundo os Códigos de Obras e Posturas, compromete a convivência harmoniosa de vizinhos. A engenharia civil deve dar essa solução a contento. Valendo-se de equipamento especializado para medição, foi mostrado que com vários tipos de revestimentos comuns sobrepostos, de maneira a dificultar a passagem sonora; o isopor, a argamassa, a malha de arame, o carpete e a alvenaria colaboram no isolamento acústico para que um edifício mantenha a intensidade sonora vibrante no seu interior e apenas o volume equivalente ao de uma simples conversação chegue a pedestres e vizinhos. Teve-se neste trabalho uma emissão sonora no interior do templo muito acima da permitida; cerca de $60 \mathrm{db}$ maior que a norma da ABNT. Mesmo assim, o isolamento garantiu apenas $10 \mathrm{~dB}$ (irrelevante para padrões de volume captados por ouvido humano) de extravaso da norma no passeio público e, sendo que, no terreno vizinho a intensidade máxima de volume ficou $05 \mathrm{~dB}$ abaixo do máximo admitido pela ABNT. Se houvesse aplicação de material mais específico e especializado do mercado, ter-se-ia um isolamento mais eficiente ainda, deixando o som que chegaria ao passeio dentro do máximo da ABNT, $55 \mathrm{~dB}$. Com tudo isso, fica o registro de que com um trabalho profissional eficiente e um pouco de investimento em acústica, torna viável qualquer empreendimento que, em um ambiente urbano fechado, precise de uma quantidade de público ouvindo e produzindo sons em escalas mais elevadas.

\section{Referências}

ARAÚJO, M. A. Controle de ruído ambiental no Brasil. Rio de Janeiro: Laboratório de ensaios acústicos do IMETROBrasil, 2005. Disponível em:<http://docplayer.com.br/11192373-Marco-antonio-nabuco-de-araujo-laboratorio-deensaios-acusticos-inmetro-brasil.html>. Acesso em: 1 maio 2014.

ASSOCIAÇÃO BRASILEIRA DE NORMAS TÉCNICAS. NBR10151: avaliação de ruídos em áreas habitadas, visando o conforto da comunidade: procedimento. Rio de Janeiro, 2000.

ASSOCIAÇÃO BRASILEIRA DE NORMAS TÉCNICAS. NBR10152: níveis de ruídos para conforto acústico. Rio de Janeiro, 1987.

AUDIO nas igrejas. Disponível em: <http://www.audionasigrejas.org.>. Acesso em: 9 maio 2014.

BISTAFA, S. R. Acústica aplicada ao controle do ruído. São Paulo: Blücher, 2006.

BRASIL. Constituição (1988). Constituição da República Federativa do Brasil: promulgada em 05 de outubro de 1988. São Paulo: Saraiva, 2013. 448p.

CONSELHO NACIONAL DE MEIO AMBIENTE. Dispõe sobre critérios de padrões de emissão de ruídos decorrentes de quaisquer atividades industriais, comerciais, sociais ou recreativas, inclusive as de propaganda política. Resolução $\mathrm{n}^{\circ}$ 01, de 08 de março de 1990. Diário Oficial da União, Brasília, DF, 2 abr. 1990.

CONSELHO NACIONAL DE MEIO AMBIENTE. Institui em caráter nacional o Programa Nacional de Educação e Controle da Poluição Sonora - Silêncio. Resolução n. 02, de 08 de março de 1990. Diário Oficial da União, Brasília, DF, 2 abr. 1990.

ENIZ, A.; GARAVELLI, S. S. L. A contaminação acústica em ambientes escolares devido aos ruídos urbanos no Distrito Federal, Brasil. HolosEnvironment. v. 6, n. 2, p. 137-150, 2006. Disponível em: <http://www.periodicos.rc.biblioteca. unesp.br/index.php/holos>. Acesso em: 26 fev. 2014.

GONÇALVES, D. Física: termologia, óptica e ondas. Rio de Janeiro: Ao Livro Técnico, 1989.

IIDA, I. Ergonomia: projeto e produção. São Paulo: Edgard Blucher, 1990.

MINAS GERAIS. Lei Estadual no 10.100, de 17 de janeiro de 1990. Dá nova redação ao artigo $2^{\circ}$ da Lei no 7.302, de 21 de julho de 1978, que dispõe sobre a proteção contra a poluição sonora no Estado de Minas Gerais. Diário do Executivo, 18 jan. 1990.

MOSCATTI, S. R. Desempenho acústico de templos e igrejas: subsídio à normalização. 2013. 172f. Dissertação (Mestrado em Arquitetura e Urbanismo) - Faculdade de Arquitetura e Urbanismo, Universidade de São Paulo, São Paulo, 2013.

SANTARÉM. Lei 17894, de 15 de dezembro de 2004. Institui o Código Ambiental do Município de Santarém e dá outras providências. Disponível em: <http://sapl.santarem.pa.leg.br/consultas/norma_juridica/norma_juridica_mostrar_ 
proc?cod_norma=370 >. Acesso em: 13 fev. 2014.

SANTARÉM. Lei n. 19.207, de 28 de dezembro de 2012. Dá nova redação ao Código de Posturas do Município de Santarém e dá outras providências. Disponível em: <http://sapl.santarem.pa.leg.br/consultas/norma_juridica/norma_ juridica_mostrar_proc?cod_norma=64 >. Acesso em: 13 fev. 2014.

SANTARÉM. Lei no 19.191, de 12 de dezembro de 2012. Dá nova redação código de obras do município de santarém, e dá outras providências. Disponível em: $<$ http://sapl.santarem.pa.leg.br/consultas/norma_juridica/norma_juridica_ mostrar_proc?cod_norma=62>. Acesso em: 13 fev. 2014.

Sobre os autores

\section{Manoel José Oliveira da Cruz}

Mestre em Processos Construtivos e Saneamento Urbano pelo EDETEC/UFPA (2012), Especialista em Metodologia na Educação Superior pela FACINTER (2012), possui graduação em Engenharia Civil pela Universidade Federal do Pará (1992), com curso paralelo de Drenagem Superficial Urbana pela ABES. Atualmente é professor na Universidade Federal do Oeste do Pará, concursado para a disciplina de Desenho Técnico Rural. Tem experiência na área de Física desde 1993, com especialização em Física Geral (UFPA).

\section{Dênio Ramam Carvalho de Oliveira}

Possui graduação em Engenharia Civil pela Universidade Federal do Pará (1995), mestrado em Estruturas e Construção Civil pela Universidade de Brasília (1998), doutorado em Estruturas (Sandwich: Imperial College, Londres) pela Universidade de Brasília (2003) e Pós-Doutorado em Estruturas pelo Imperial College de Londres, Inglaterra (2007). Atualmente é professor adjunto da Universidade Federal do Pará. Tem experiência na área de Engenharia Civil, com ênfase em Estruturas de Concreto, atuando principalmente nos seguintes temas: concreto armado, dimensionamento, laje lisa, cisalhamento, torção, concreto de alta resistência, concreto pré-moldado, reforço estrutural e novos materiais. 